\title{
Endoscopic postdilatation application of Mitomycin C in children with resistant esophageal strictures
}

\author{
Yasser K. Rashed, MD1, Mohamed El-Guindi, MD² \\ ${ }^{1}$ Department of Pediatric Hepatology, National Liver Institute, Menoufiya University, Menoufia, ${ }^{2}$ Department of Pediatric Hepatology, Gastroenterology and \\ Nutrition, National Liver Institute, Menoufia University, Menoufia, Egypt
}

Background: The esophagus is the most common part of gastrointestinal (Gl) tract at the risk of stricture. Benign disorders are the leading causes of narrowing. Caustic ingestion is the most common cause of esophageal stricture in children, especially in developing countries. Clinical responses to the topical application of Mitomycin $\mathrm{C}$ in various medical procedures have been reported.

Purpose: The study aimed to evaluate the methodology, efficacy, and side effects of Mitomycin C in the treatment of esophageal strictures.

Methods: This study included 30 children with resistant esophageal strictures. Upper Gl endoscopy was performed up to the area of stricture, esophageal dilatation was done, endoscopy was repeated, and Mitomycin C was applied topically under direct endoscopic vision. The effect of the procedure was followed over a period of $3-5$ years.

Results: The response to Mitomycin C was excellent (clinically and endoscopically) in 28 patients (93.3\%) and good (endoscopically only) in 2 patients (6.7\%). No side effects of topical Mitomycin C in children with esophageal strictures were reported in this study.

Conclusion: Esophageal dilatation followed by local Mitomycin C application may be a useful strategy for treating resistant esophageal strictures.

Key words: Esophageal stricture, Mitomycin C, Corrosive esophagitis

\section{Introduction}

Esophageal strictures can occur in children, corrosives materials still the most important cause of stricture in children and constitute $80 \%$ of the cases. ${ }^{1)}$ Dysphagia occurs when stenosis constitutes half of the esophageal lumen. ${ }^{2)}$

Endoscopic conservative management of esophageal strictures has evolved first-line management, rather than more aggressive surgical substitution. Endoscopic dilatation of esophageal strictures is a successful method for treating such cases in more than $80 \%$ of cases.

Endoscopic balloon dilatation or bougies (Savary) are the initial step to treat esophageal strictures. Intraluminal stent is another endoscopic technique to treat esophageal strictures and to get patent esophageal lumen. Re stenosis still the main problem. ${ }^{4}$

Mitomycin $\mathrm{C}$ has been well documented in various ophthalmologic procedures and laryngeal/tracheal conditions where it has been shown that Mitomycin C inhibited fibroblast proliferation. Use of Mitomycin C has been reported in caustic stricture of the esophagus. ${ }^{5}$

The aim of this study was to evaluate the methodology, efficacy, and side effects of Mitomycin C application after GI endoscopic dilatation of resistant esophageal strictures in children.
Corresponding author: Yasser K. Rashed, MD Department of Pediatric Hepatology, Gastroenterology and Nutrition, National Liver Institute, Menoufia University, 32511 Shebin El-koom, Menoufia, Egypt

Tel: +2-048-222-2740

Fax: +2-048-223-4586

E-mail: yasserrashed79@yahoo.com https://orcid.org/0000-0001-9484-1238

Received: 7 October, 2018

Revised: 17 June, 2019

Accepted: 22 June, 2019

\section{Copyright (C) 2019 by The Korean Pediatric Society}

This is an open-access article distributed under the terms of the Creative Commons Attribution NonCommercial License (http://creativecommons.org/ licenses/by-nc/4.0/) which permits unrestricted noncommercial use, distribution, and reproduction in any medium, provided the original work is properly cited. 


\section{Methods}

This study included 30 children with one or more features of resistant esophageal stricture. Seventeen males and 13 females, their ages ranged from 16-168 months with a mean of 57.6 months. They were admitted to the Pediatric Endoscopy Unit in the Pediatric Hepatology Department - National Liver Institute - Menoufiya University Egypt. The diagnosis of esophageal strictures based on clinical history, barium study and upper gastrointestinal (GI) endoscopy.

All patients in the study were subjected to full history taking including demographic data, the time of exposure, the nature of corrosives they ingested, and their dietary history. Thorough clinical examination was done with special interest in weight, height, and nutritional status. Laboratory investigations included full blood count, liver function tests, chest X-ray. Barium study and upper GI endoscopy were undergone aiming to diagnose the nature and extent of esophageal stricture.

\section{Types of strictures}

Resistant strictures were usually $>2 \mathrm{~cm}$ long, severely narrowed lumen $<7 \mathrm{~mm}$, these strictures need more than 5 esophageal dilatation settings, with a high tendency to recur despite optimal dilatation procedure. Esophageal stricture was considered simple if there are no features of resistant esophageal stricture.

The procedure was done under general anesthesia. Upper GI endoscopy was done first until reaching the area of stenosis, then gauge wire was passed into the stomach and esophageal dilators bougie were introduced subsequently under X-ray screen. The endoscope was reintroduced for topical application of |Mitomycin C (2 mg dissolved in 20-mL saline) on the stenotic area under direct vision. This was done by either front-loading the pledget in a standard cap used for band ligation of varices attached to the end of the endoscope (group $1, \mathrm{n}=16$ patients), or by topical spraying of Mitomycin using the injection needle on the affected mucosa (group $2, n=14$ patients). We compared the pledget and spray methods regarding the effect and side effects.

The response to Mitomycin C application classified according to the clinical and endoscopic findings, clinical and endoscopic followup continued for 3-5 years the response classified according to the followings:

- Excellent: excellent improvement regarding both clinical and endoscopic findings.

- Partly improved: partly improvement of both findings not allowing normal swallowing and weight gaining.

- Poor response: no improvement including the endoscopic and clinical findings (dysphagia).

Endoscopic criteria of improvement: is the passage of pediatric endoscopy with diameter $30 \mathrm{FC}$ in diameter without any resistance, in addition, no inflammatory endoscopic features.

Clinical improvement criteria: no difficulty of swallowing

\section{Follow-up}

The effect of the procedure followed for 3-5 years post application. Two patients need post Mitomycin application twice dilation over 4-year follow-up. Radiological assessment by barium swallow study was done and endoscopic evaluation of the esophagus was performed for the assessment of the integrity and size of esophageal lumen at the stricture site.

\section{Ethical points}

The study was revised and approved by the local ethical committee and Institutional Review Board (IRB) of National Liver Institute. The study followed the ethical standards of the National Liver InstituteMenofiya University- Egypt, committee (IRB00003413). During the interview, the respondents (parents) of the children were simply informed about the aims of this study. Written consent was taken from the Parents who accompanied the child during attending the mentioned hospitals before participating in the research.

\section{Results}

Caustic potash ingestion was the cause of esophageal stricture formation in 23 patients (76.66\%) as shown in Table 1, which determined by careful history taking and/or observing the containing bottle by the family. Post reflux occurred in one patient, and postsclerotherapy in another patient. The etiology was not discovered in 5 patients. Our results showed $80 \%$ of our patients were $\leq 5$ years. Males were 17 while females were 13 of our patients. Twenty patients of our caustic ingestion patients had history of accidental ingestion of household cleaners (Potash).

Upper endoscopy was performed in all of the patients and while Gastrografin/barium upper GI series was performed in 10 patients before endoscopy. The median diameter of the stricture was 1.5 $\mathrm{mm}$ (range, 1-5 mm) which determined by barium or by upper GI endoscope. The length of the stricture at diagnosis was ranged from $10-110 \mathrm{~mm}$ with the mean of $37.14 \mathrm{~mm}$.

Before Mitomycin application, repeated dilation procedures in 21 patients ranging from 2-75 with the mean of 12 times. Nine patients had no history of previous dilatation while number of dilatation settings with Mitomycin applications ranged from one to 5 with the mean of 2.3 times

Before the application of Mitomycin C, endoscopic dilation setting repeated every 2 weeks ( $2.52 \pm 1.44$ weeks), this duration was prolonged to $5.00 \pm 4.39$ weeks after the application of Mitomycin C.

Patient No. 1 required 75 dilatation settings before the application of Mitomycin C. This patient was 5 years female child presented with severe dysphagia, the length of stricture was $11 \mathrm{~cm}$, which diagnosed with barium and upper GI endoscope, with repeated dilatation the length of stricture improved, but only $1 \mathrm{~cm}$ resist further dilatation, and we tried Mitomycin $\mathrm{C}$ application, and then 


\begin{tabular}{|c|c|c|c|c|c|c|c|c|c|c|c|c|c|}
\hline $\begin{array}{l}\text { Case } \\
\text { No. }\end{array}$ & $\begin{array}{l}\text { Age } \\
(\mathrm{mo})\end{array}$ & Sex & $\begin{array}{l}\text { Length of } \\
\text { stricture } \\
\text { (mm) }\end{array}$ & Cause & Diagnosis & $\begin{array}{l}\text { Diameter } \\
(\mathrm{mm})\end{array}$ & $\begin{array}{c}\text { No. of } \\
\text { dilatation } \\
\text { setting } \\
\text { before MC }\end{array}$ & $\begin{array}{c}\text { Interval } \\
\text { between } 2 \\
\text { endoscopic } \\
\text { settings (wk) }\end{array}$ & $\begin{array}{c}\text { No of } \\
\text { dilatation } \\
\text { with MC }\end{array}$ & $\begin{array}{l}\text { Interval between } \\
\text { endoscopic } \\
\text { setting } \\
\text { (MC) (wk) }\end{array}$ & Response & $\begin{array}{l}\text { Route of } \\
\text { application }\end{array}$ & $\begin{array}{l}\text { Compli- } \\
\text { cations }\end{array}$ \\
\hline 1 & 60 & $\mathrm{~F}$ & 110 & Corrosive & $\begin{array}{l}\text { Gastrografin and upper } 1 \\
\text { Gl endoscopy }\end{array}$ & & 75 & $2-3$ & 4 & 4 & Good & Spray & No \\
\hline 2 & 56 & M & $70-75$ & & & 1 & 45 & $2-3$ & 2 & 4 & Excellent & Spray & No \\
\hline 3 & 36 & $M$ & $13-15$ & & & 1 & 9 & $2-4$ & 2 & 4 & Excellent & Spray & No \\
\hline 4 & 42 & M & 30-35 & & & 2 & 7 & $2-4$ & 2 & 4 & Excellent & Spray & No \\
\hline 5 & 72 & $\mathrm{~F}$ & 30-35 & & & 5 & 3 & 2 & 1 & 0 & Excellent & Spray & No \\
\hline 6 & 50 & $\mathrm{~F}$ & $35-40$ & Reflux & & 3 & 11 & 4 & 1 & 0 & Excellent & Pledget & No \\
\hline 7 & 35 & $\mathrm{~F}$ & $15-20$ & Corrosive & & 1 & 22 & $2-4$ & 3 & $3-4$ & Excellent & Pledget & No \\
\hline 8 & 75 & $\mathrm{M}$ & $40-45$ & & & 2 & 18 & $4-6$ & 2 & 4 & Excellent & Pledget & No \\
\hline 9 & 41 & $M$ & $25-30$ & & & 1 & 12 & 4 & 2 & 4 & Excellent & Pledget & No \\
\hline 10 & 70 & $\mathrm{~F}$ & $45-50$ & & & 4 & 8 & 4 & 2 & 4 & Excellent & Pledget & No \\
\hline 11 & 35 & $\mathrm{M}$ & 40 & Unknown & & 1 & 4 & 4 & 1 & 0 & Excellent & Pledget & No \\
\hline 12 & 40 & M & 30 & Corrosive & Upper Gl endoscopy & 3 & 4 & 3 & 2 & 8 & Excellent & Pledget & No \\
\hline 13 & 144 & $\mathrm{~F}$ & 30 & Sclero & & 2 & 5 & 2 & 1 & 0 & Excellent & Pledget & No \\
\hline 14 & 60 & M & 50 & Corrosive & & 3 & 5 & $2-4$ & 3 & 8-12 & Excellent & Pledget & No \\
\hline 15 & 22 & $\mathrm{~F}$ & 30 & & & 1 & 10 & $2-4$ & 3 & 8-12 & Excellent & Pledget & No \\
\hline 16 & 16 & $M$ & 30 & Unknown & & 4 & 4 & 2 & 2 & $8-12$ & Excellent & Pledget & No \\
\hline 17 & 23 & $\mathrm{~F}$ & 25 & Corrosive & & 2 & 4 & $2-4$ & 3 & $8-12$ & Excellent & Pledget & No \\
\hline 18 & 72 & $\mathrm{~F}$ & 40 & & & 1 & 12 & $2-4$ & 4 & 8-12 & Excellent & Pledget & No \\
\hline 19 & 36 & $F$ & 30 & Unknown & & 1 & 3 & $2-4$ & 1 & 0 & Excellent & Pledget & No \\
\hline 20 & 168 & M & 70 & Corrosive & & 1 & 16 & 2 & 5 & 5 & Good & Pledget & No \\
\hline 21 & 28 & M & 30 & & & 1 & 6 & 2 & 3 & 4 & Excellent & Pledget & No \\
\hline 22 & 30 & M & 24 & & & 2 & 3 & 2 & 2 & 4 & Excellent & Spray & No \\
\hline 23 & 40 & $M$ & 35 & & & 2 & 3 & 2 & 2 & 4 & Excellent & Spray & No \\
\hline 24 & 42 & $\mathrm{~F}$ & 40 & Unknown & & 1 & 3 & 2 & 1 & 6 & Excellent & Spray & No \\
\hline 25 & 54 & $F$ & 10 & & & 2 & 6 & 2 & 2 & 4 & Excellent & Spray & No \\
\hline 26 & 39 & M & 25 & Corrosive & & 2 & 4 & 2 & 2 & 4 & Excellent & Spray & No \\
\hline 27 & 44 & $M$ & 10 & & & 2 & 7 & 2 & 2 & 4 & Excellent & Spray & No \\
\hline 28 & 40 & $\mathrm{~F}$ & 10 & & & 5 & 7 & 2 & 2 & 4 & Excellent & Spray & No \\
\hline 29 & 50 & M & 15 & & & 5 & 7 & 2 & 2 & 4 & Excellent & Spray & No \\
\hline 30 & 56 & M & 10 & & & 5 & 5 & 2 & 2 & 4 & Excellent & Spray & No \\
\hline
\end{tabular}

MC, Mitomycin C; Gl, gastrointestinal; Sclero, sclerotherapy.

started the idea to extent the study.

Excellent improvement regarding both clinical and endoscopic findings seen in 28 patients (93.3\%) while partly improving seen in 2 (6.7\%), we did not find any patient with poor response in this study. There were no complications related to the Mitomycin application in both studied group.

Follow-up of our patients for 3-5 years did not show any complications related to the procedures itself or to Mitomycin C, the results of both pledget and spray methods nearly the same without any difference regarding the side effects which encourage the use of spray method as it easier for the endoscopist and shorter in duration.

\section{Discussion}

Repeated sessions of dilatation required in severe esophageal strictures due to restenosis. The cause of restenosis can be explained by intense fibrogenesis during healing and after the traumatic dilatation procedure, making repeated dilatations necessary with an increased risk of complications and perforation.

Failure of dilatation of long and resistant strictures with repeated dilatation has been associated with psychological problems, withdrawal from school, hospital fears, and familial problems. In our center, trials to decrease the number of dilatations started with trial of steroid injection in localized strictures to increase the intervals but 
appeared not effective.

Trial of Mitomycin C (MMC) application on localized strictures has shown better outcome with less number of dilatation sessions. In our center, the first MMC application done in a very resistant case described above, whose stricture started as $11 \mathrm{~cm}$ long and esophageal lumen was very tight, and then showed marked improvement of the dysphagia with a decrease in the number of dilatations after MMC application.

The data published in children, most cases of esophageal strictures caused by ingestion of caustic substances, peptic esophagitis, or after anastomotic surgery done for EA. ${ }^{7)}$ this run in harmony with our results as $76.66 \%$ of our patients got esophageal stricture due to accidental caustic ingestion.

The majority of patients were under the age of 5 years and boys are more often affected than girls, this in agreement with most of the studies done on children. ${ }^{8)}$

Corrosives may be either acidic or alkaline substances. The most common corrosive caused caustic esophageal injuries were household cleaners, mostly alkaline. In children, ingestions are often accidental; the severity of injury depends upon amount, type and concentration of the ingested corrosive substance.

Alkaline agents leading to rapid liquefaction necrosis and persistent ulceration and fibrosis for months, contiguous damage occurs from the esophagus to the stomach and beyond while acidic agents cause more superficial coagulation necrosis with scarring that may limit the extent of injury, and the stomach is more affected than the esophagus. ${ }^{9)}$ Mitomycin C tried in extra gastrointestinal lesions after internal optical urethrotomy, Mitomycin C is effective in preventing recurrence of urethral stricture. ${ }^{10)}$

In our study, gastro-esophageal reflux disease (GERD) with resultant peptic injury was the cause of esophageal stricture in only one patient (Table 1). This was different from that reported by ElSerag ${ }^{11)}$ and Spechler et al. ${ }^{12)}$ who they found GERD with resultant peptic injury is the most common cause of benign esophageal strictures. The difference with our results may be because he studied different age group or different number of patients. Typically, these strictures are located near the gastro-esophageal junction and are relatively short $(1-2 \mathrm{~cm})$ in length.

Mitomycin C applied to stricture mucosa after dilatation. Various techniques have been used to topically deliver Mitomycin C to the anastomotic stricture. Mucosal application of Mitomycin $\mathrm{C}$ has been shown to be an effective and safe treatment without complications detected in our patients. This in agreement with Heran et al.,", ${ }^{13)}$ who studied 2 cases and used Mitomycin C to the disrupted stricture through the gastrostomy tract, and used a $12 \mathrm{~F}$ to $16 \mathrm{~F}$ semirigid sheath introduced over a guide wire and passed retrograde up the esophagus to the stricture. Also Rosseneu et al. ${ }^{14)}$ found that postdilation application of topical Mitomycin $\mathrm{C}$ had major success in $62.5 \%$ of patients and partial success in $18.7 \%$.

Gusmon-Oliveira et al. ${ }^{15)}$ concluded that the repeated injection in the short interval of MMC in refractory pharyngoesophageal stenosis in patients after head and neck cancer is not recommended, this finding was in great difference with our results, this can be easily explained by different age group and different nature of both diseases.

Finally, we can conclude that Mitomycin C topical application can be safely tried for patients with caustic esophageal stricture, reducing the number of required dilatation sessions. It should be considered as an adjunct new modality before decision of more invasive therapeutic modalities. However, more studies on larger number of patients will be needed to prove the efficacy of MMC in these patients.

\section{Conflicts of interest}

No potential conflict of interest relevant to this article was reported.

\section{Acknowledgments}

Thanks to all anesthetists and technicians that help us during the procedures.

\section{References}

1. Contini S, Scarpignato C. Caustic injury of the upper gastrointestinal tract: a comprehensive review. World J Gastroenterol 2013;19:391830.

2. Khan KM. Endoscopic management of stricture in pediatrics. Tech Gastro Endosc 2013;15:25-31.

3. Abreu M, Nunes I, Corujeira S, Tavares M, Trindade E, Dias JA. Caustic esophageal stenosis: a case report of endoscopic dilation with a dynamic stent. GE Port J Gastroenterol 2016;23:218-23.

4. Wang H, Tan L, Feng M, Zhang Y, Wang Q. Comparison of the shortterm health-related quality of life in patients with esophageal cancer with different routes of gastric tube reconstruction after minimally invasive esophagectomy. Qual Life Res 2011;20:179-89.

5. Berger M, Ure B, Lacher M. Mitomycin C in the therapy of recurrent esophageal strictures: hype or hope? Eur J Pediatr Surg 2012;22:10916.

6. Lan LC, Wong KK, Lin SC, Sprigg A, Clarke S, Johnson PR, et al. Endoscopic balloon dilatation of esophageal strictures in infants and children: 17 years' experience and a literature review. J Pediatr Surg 2003;38:1712-5.

7. Li H, Liu Y, Shu XZ, Gray SD, Prestwich GD. Synthesis and biological evaluation of a cross-linked hyaluronan-mitomycin C hydrogel. Biomacromolecules 2004;5:895-902.

8. Noel RJ, Rothenberg ME. Eosinophilic esophagitis. Curr Opin Pediatr 2005; 17:690-4.

9. Pearson EG, Downey EC, Barnhart DC, Scaife ER, Rollins MD, Black $\mathrm{RE}$, et al. Reflux esophageal stricture--a review of 30 years' experience in children. J Pediatr Surg 2010;45:2356-60. 
10. Ali L, Shahzad M, Orakzai N, Khan I, Ahmad M. Efficacy of mitomycin $\mathrm{C}$ in reducing recurrence of anterior urethral stricture after internal optical urethrotomy. Korean J Urol 2015;56:650-5.

11. El-Serag HB. Temporal trends in new and recurrent esophageal strictures in Department of Veterans Affairs. Am J Gastroenterol 2006; 101:1727-33.

12. Spechler SJ, Lee E, Ahnen D, Goyal RK, Hirano I, Ramirez F, et al. Long-term outcome of medical and surgical therapies for gastroesophageal reflux disease: follow-up of a randomized controlled trial. JAMA 2001;285:2331-8.

13. Heran MK, Baird R, Blair GK, Skarsgard ED. Topical mitomycin-C for recalcitrant esophageal strictures: a novel endoscopic/fluoroscopic technique for safe endoluminal delivery. J Pediatr Surg 2008;43:8158.

14. Rosseneu S, Afzal N, Yerushalmi B, Ibarguen-Secchia E, Lewindon P, Cameron D, et al. Topical application of mitomycin-C in oesophageal strictures. J Pediatr Gastroenterol Nutr 2007;44:336-41.

15. Gusmon-Oliveira CC, Kuboki YM, de Paulo GA, de Lima MS, Uemura RS, Martins BC, et al. Endoscopic injection of mitomycin C for the treatment of pharyngoesophageal stenosis refractory to endoscopic treatment with dilatation in patients treated for head and neck cancer. Gastroenterol Res Pract 2018;2018:5428157. 